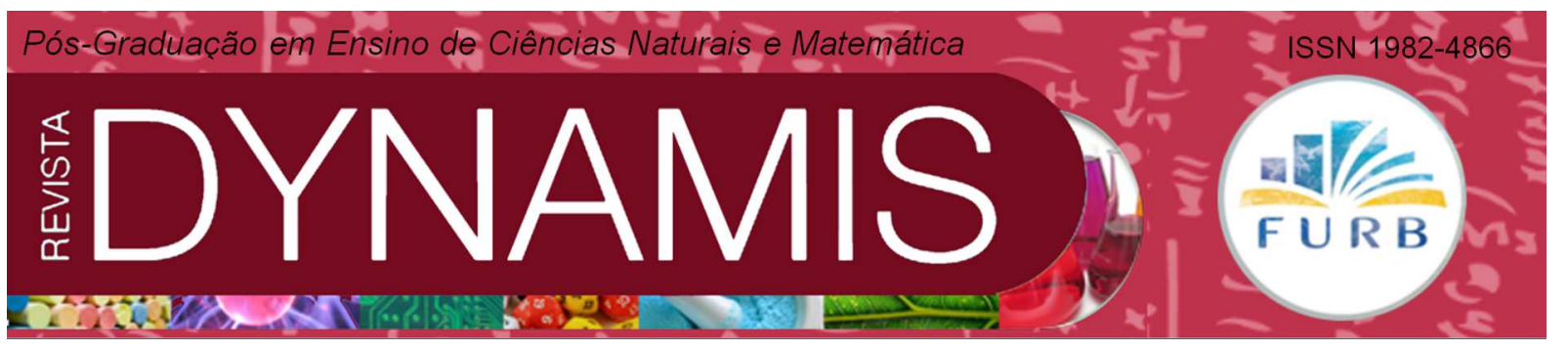

\title{
FORMAÇÃO DE PROFESSORES (DE MATEMÁTICA): TEXTOS E CONTEXTOS DE UMA CAMPANHA
}

Teachers formation (of mathematics): texts and contexts of a campaign

Rosinéte Gaertner

Programa de Pós-Graduação em Ensino de Ciências Naturais e Matemática - PPGECIM/FURB Universidade Regional de Blumenau

rogaertner@gmail.com

Ivete Maria Baraldi

Programa de Pós-Graduação em Educação Matemática - UNESP - Rio Claro Programa de Pós-Graduação em Educação para Ciências - UNESP - Bauru ivete.baraldi@fc.unesp.br 


\title{
Resumo
}

Neste artigo apresentamos traços históricos gerais sobre a Campanha de Aperfeiçoamento e Difusão do Ensino Secundário (Cades) e sobre suas publicações. De total desconhecida à multifacetada, a Cades mostrou-se como um importante veículo dos ideais da época, décadas de 1950 e 1960, no que diz respeito à formação de professores e uma maneira dos docentes se aperfeiçoarem, discutirem e formalizarem sua prática quando ainda, no Brasil, era raro um lócus para tal exercício. Essa Campanha, até os dias atuais, foi quase que totalmente ignorada pelos pesquisadores da História da Educação (Matemática), o que nos leva a acreditar que, muitas vezes, quando se estuda a formação de professores, se adota uma postura elitista e centralizadora, focando somente os grandes centros e partindo de instituições de ensino consideradas tradicionais. Hoje em dia, ousamos afirmar que, mediante a dimensão continental brasileira, quem for se embrenhar nos estudos relacionados à formação de professores, principalmente nas regiões interioranas e no período de realização da Campanha, não pode deixar de olhar para a Cades. Este trabalho é parte de uma pesquisa em História da Educação Matemática, cujo objetivo foi o de investigar a Cades, utilizando tanto a história oral quanto a pesquisa bibliográfica e documental.

Palavras-chave: Ensino Secundário Brasileiro. Cades. Produção Bibliográfica. Educação Matemática.

\begin{abstract}
This article presents general historical features on the Campanha de Aperfeiçoamento e Difusão do Ensino Secundário (Cades) and about their publications. Totally unknown to the multifaceted, "Cades" proved to be an important vehicle of the ideals of that time, the 1950s and 1960s. In regard to the formation of teachers and a way for teachers to improve themselves, discuss and formalize their practice as yet, in Brazil, it was rare a locus for such an exercise. This Campaign, to this day, has been almost entirely ignored by researchers of History of Education (Mathematics), which leads us to believe that, often when studying teachers formation, is adopted an elitist and centralizing stance focusing on only the major centers and building educational institutions considered traditional. We dare saying that by Brazil's continental dimensions, whoever is engrossed in studies related to teachers formation, especially in the country side and the realization of the campaign period, can not stop looking for "Cades". This work is part of research in the History of Mathematics Education, whose objective was to investigate "Cades", using both oral history as bibliographic and documentary research.
\end{abstract}

Keywords: Brazilian Secondary Education. Cades. Bibliographic Production. Mathematics education. 


\section{INTRODUÇÃO}

Este trabalho apresenta uma pesquisa cujo objetivo foi o de investigar a Campanha de Aperfeiçoamento e Difusão do Ensino Secundário - Cades, utilizando tanto a história oral quanto a pesquisa bibliográfica e documental.

Essa investigação sobre a Cades surgiu após nossos trabalhos de doutoramento, Baraldi (2003) e Gaertner (2004), pois percebemos que, embora tivéssemos entrevistados professores de Matemática de duas regiões bastante distintas de nosso país (Bauru - interior do Estado de São Paulo e Blumenau - interior de Santa Catarina), eles (professores) receberam a mesma formação inicial remedial - que, muitas vezes, procurava apenas regulamentar uma prática docente que já existia - nas décadas de 1950 e 1960, por meio da Cades. Embora em Baraldi (2003) possa ser encontrada uma discussão sobre a Cades, esta ainda se mostrava bastante desconhecida, pois é pouco explorada no contexto da história da educação brasileira.

Nesse artigo, temos como objetivo mostrar este nosso trabalho como contribuição para a História da Educação (Matemática) no que diz respeito à formação de professores, bem como de fomentar discussões sobre as possibilidades de formação docente. Para tanto, apresentamos traços históricos gerais sobre a Campanha e sobre suas publicações em formatos de livros e de artigos na Revista Escola Secundária.

\section{A CADES E A FORMAÇÃO DE PROFESSORES PARA O ENSINO SECUNDÁRIO}

Nas escolas secundárias brasileiras, durante a década de 1940, poucos professores tinham formação de nível superior. Estes poucos eram formados em faculdades de Filosofia ou ainda nas escolas politécnicas ou militares. Apesar de ser precária a formação docente, a expansão do ensino secundário no país foi acelerada, sendo que, em 1932 havia 342 estabelecimentos com 65.000 alunos e em 1954 havia o registro de 1.771 ginásios com rol de matrículas de 536.000 alunos, evidenciando um crescimento de 500\% em vinte e cinco anos (MATTOS, 1957). Mas, apesar deste crescimento quantitativo, faltou à escola secundária o correspondente crescimento qualitativo, sendo o seu ponto mais crítico a precária formação do professores, como publicado no primeiro número da Revista Escola Secundária:

\footnotetext{
Ainda hoje, decorridos quase 20 anos da criação dessas faculdades [as de Filosofia], cêrca de $16 \%$ dos 40000 professores secundários militantes tiveram a oportunidade de nelas adquirir uma adequada formação profissional: $84 \%$ desse exército de professôres são ainda autodidatas. (MATTOS, 1957, p.8)
}

Para suprir a defasagem quanto à formação acadêmica dos professores, em 1953, no governo do presidente Getúlio Vargas (1951-1954), foi criada a Campanha de Aperfeiçoamento e Difusão do Ensino Secundário (Cades) a partir do Decreto $n^{\circ} 34.638$, de 14 de novembro de 1953. Esta Campanha tinha por objetivos difundir e elevar o nível do ensino secundário, ou seja, tornar a educação secundária mais ajustada aos interesses e necessidades da época, conferindo ao ensino eficácia e sentido social, bem como criar possibilidades para que os mais jovens tivessem acesso à escola secundária. Para atingir esses 
objetivos, promoveu cursos e estágios de especialização e aperfeiçoamento para professores, técnicos e administradores de estabelecimentos de ensino secundário; concedeu bolsas de estudo a professores secundários para realizarem cursos ou estágios de especialização e aperfeiçoamento, promovidos por entidades nacionais ou estrangeiras; criou o serviço de orientação educacional nas escolas de ensino secundário, entre tantas outras ações.

Pinto (2008) identificou quatro momentos distintos na história da Cades: do anúncio à implantação (1953 - 1956); consolidação e expansão (1956 - 1963); renovação administrativo-pedagógica (1963 - 1964); declínio e desaparecimento (1964 - 1970).

No primeiro deles, a Diretoria do Ensino Secundário estava sob a responsabilidade de Armando Hildebrand que, segundo Pinto (2008), procurou concretizar as metas traçadas para a Cades e logo no primeiro semestre de 1954 promoveu os primeiros cursos de orientação para os professores inscritos no exame de suficiência. Posteriormente, promoveu outros cursos também direcionados aos diretores e secretários de escolas.

Espalhadas por todo o país, à época da criação da Cades, existiam as Inspetorias Seccionais do Ensino Secundário, instâncias "menores", subordinadas às Secretarias Estaduais de Educação, responsáveis pela administração do ensino nas cidades. A partir de 1956, a Campanha passou a promover, nas inspetorias seccionais, cursos intensivos de preparação aos exames de suficiência que, de acordo com a Lei $n^{\circ} 2.430$, de 19 de fevereiro de 1955, conferiam aos aprovados o registro de professor do ensino secundário e o direito de lecionar onde não houvesse disponibilidade de licenciados por faculdade de filosofia. Esses cursos, geralmente, tinham a duração de um mês (janeiro ou julho) e eram elaborados a fim de suprir as deficiências dos professores, até então leigos, referentes aos aspectos pedagógicos e aos conteúdos específicos das disciplinas que iriam lecionar ou que já lecionavam nas escolas secundárias.

Em 1956, foi nomeado diretor do ensino secundário, pelo então presidente Juscelino Kubitschek, Gildásio Amado. Neste segundo período, as ações da CADES foram ampliadas e os cursos foram espalhados por todo o Brasil, via inspetorias seccionais. Para que, realmente, todas as regiões brasileiras fossem contempladas pela Cades, foram criadas as "missões pedagógicas”, definidas pelo Ofício Circular no 15, de 10 de março de 1960, como equipes volantes compostas por membros treinados e que possuíssem experiência no magistério devidamente reconhecida. Ainda, diversas outras metas que foram traçadas no decreto de sua instituição foram alcançadas, e o professor José Carlos de Mello e Souza foi convidado para coordenar a Campanha.

O terceiro período destacado pela autora é aquele em que se deu o golpe militar. À época, Lauro de Oliveira Lima foi nomeado como diretor do ensino secundário. Seu nome surgiu devido ao trabalho renovador que havia efetuado na Inspetoria Seccional do Ensino Secundário do Ceará. Conforme Pinto (2008), ao ser nomeado, Lauro apresentou um detalhado plano de ações, com justificativas sociológicas, pedagógicas e administrativas. No entanto, com o golpe e a aliança de Lauro com as ideias de esquerda, o período de renovação foi interrompido. Lauro de Oliveira Lima foi afastado de seu cargo e de qualquer possibilidade de trabalho como inspetor federal de ensino.

O quarto e terminal período da Cades conta com Gildásio Amado novamente à frente da Diretoria do Ensino Secundário. Porém, diferentemente de sua gestão anterior, segundo Pinto 
(2008), somente os cursos de orientação para os exames de suficiência foram oferecidos nos anos de 1965, 1966, 1967 e 1969. Tanto no trabalho de Pinto (2008) quanto no de Baraldi (2003), não foi possível precisar uma data e as fontes orais e escritas não forneceram motivos para a extinção da Cades. Dessa maneira, podemos levar em consideração algumas hipóteses levantadas pela primeira autora: a Cades sofreu de inanição, o que seria de se esperar de uma campanha que, normalmente, é criada para responder a determinadas demandas, num determinado período apenas; outra, que a expansão do ensino superior tenha colaborado com o motivo anterior e fortalecido seu apagar. Por fim, segundo as duas autoras, o golpe de misericórdia foi a Lei $n^{\circ} 5.692 / 71$, principalmente no que diz respeito às licenciaturas plenas e curtas.

\section{A CADES E AS SUAS PUBLICAÇÕES}

Além dos cursos, uma ação de fundamental importância foi a publicação de periódicos e manuais destinados à formação dos professores. Os livros editados pela Cades eram voltados para a formação pedagógica dos professores da escola secundária, com o objetivo de fornecer a eles novos métodos e técnicas de ensino. Muitos destes livros foram vencedores do concurso de monografias sobre a metodologia de diversas disciplinas do ensino secundário, concurso este promovido no dia 15 de outubro (Dia do Professor) de cada ano pela Cades.

Em nosso livro -“Textos e contextos: um esboço da CADES na História da Educação (Matemática)" (Baraldi; Gaertner, 2013) - apresentamos vários aspectos da Campanha, relacionando suas publicações e os locais onde podem ser encontradas e, ainda, descrevemos aquelas voltadas para o professor de matemática da escola secundária. No total, foram localizados e referenciados: sete livros da área de Matemática; dezenas de livros das mais diversas áreas educacionais; vários livros que discorrem sobre a Cades e suas finalidades; dezenove edições da Revista Escola Secundária - periódico produzido e distribuído sob a chancela da Campanha no período de 1957 a 1965. Estas obras orientavam os professores do ensino secundário nos aspectos curriculares, legais e didáticos. Foram localizados os seguintes livros voltados para o ensino de matemática:

- MORAES, Ceres Marques de; BEZERRA, Manoel Jairo; SOUSA, Júlio César de Mello. Apostilas de Didática Especial em Matemática. Rio de Janeiro: CADES, 1959. $220 \mathrm{p}$.

- CONGRESSO BRASILEIRO DE ENSINO DA MATEMÁTICA. Anais do $3^{\circ}$ Congresso Brasileiro de Ensino de Matemática. Rio de Janeiro: CADES, 1959. 246 p.

- HILDEBRAND, Armando; SIQUEIRA, Cleantho Rodrigues; MIRA Y LOPES, Emílio; MEDEIROS, Ethel Bauzer; MÉRICI, Imídio Giuseppe; PACHECO, Roberto José Fontes. Como Ensinar Matemática no Curso Ginasial: manual para orientação do candidato a professor de curso ginasial no interior do país. Rio de Janeiro: MEC/CADES, s.d.

- BEZERRA, Manoel Jairo. Didática Especial de Matemática. Rio de Janeiro: CADES, 1957. 76p.

- BEZERRA, Manoel Jairo. O Material Didático no Ensino da Matemática. Rio de Janeiro: CADES, 1962. 117p.

- CHAVES, João Gabriel. Didática da Matemática. Rio de Janeiro: CADES, 1960. $105 \mathrm{p}$. 
- SILVA, Maria Edmee de Andrade Jacques da. A didática da Matemática no Ensino Secundário. Rio de Janeiro: CADES, 1960. 240p.

Nas obras de Matemática há indicações de que o ensino deveria: estar de acordo com os objetivos da escola delineada para a época, levar em conta o ponto de vista psicológico da aprendizagem e ter em mente as aplicações da Matemática nas outras áreas de estudo. Tais aplicações seriam por meio de experimentações, nas quais o aluno deveria elaborar relações lógicas por si mesmo, com o auxílio do professor, descaracterizando desse modo, o "aluno passivo e receptor". Dessa maneira, a metodologia em sala de aula deveria ser diferenciada, pois o aluno deveria participar do processo de aprendizagem.

De modo geral, uma estratégia de ensino difundido para a escola secundária, à época da Cades, era a do "estudo dirigido". O primordial nesta estratégia era procurar dar aos alunos condições ambientais e de horário de estudo que, muitas vezes, não encontravam em seus lares, além de também pretender modificar o "fazer" do professor em sua aula. A utilização de materiais didáticos para promover a aprendizagem matemática era outra importante orientação difundida aos professores. Os materiais didáticos eram vistos como excelentes atrativos para a atenção dos alunos para a matemática, capazes de promover a efetiva aprendizagem se, de preferência, fossem construídos pelos estudantes.

Dentre as muitas publicações da Campanha, havia a Revista Escola Secundária, cujo primeiro exemplar foi lançado em junho de 1957. Era uma publicação trimestral publicada pela Cades, em conjunto com a Diretoria do Ensino Secundário e o MEC. À época, o diretor do Ensino Secundário era o professor Gildásio Amado, o coordenador da Cades era o professor José Carlos de Mello e Souza, irmão de Júlio César de Mello e Souza (conhecido pelo pseudônimo Malba Tahan - autor de dezenas de obras de ficção e de matemática - que foi professor por oito anos pela Cades, em diversas localidades do país) e o redator-chefe da revista era o professor Luiz Alves de Mattos.

Foram publicados dezenove números da Revista, sendo a primeira edição de 1957 e a última não tem data específica, embora seja observado que, em suas primeiras páginas, estava pronta em 1963 "mas somente agora publicada", que possibilita supormos que foi publicada na segunda metade da década de 1960.

Nas dezenove edições são encontrados artigos referentes às seguintes áreas e temas: didática geral, orientação educacional, língua vernácula, latim, línguas estrangeiras, matemática, ciências naturais, história do Brasil, geografia, trabalhos manuais e economia doméstica, desenho, física, química, filosofia e educandários nacionais. Com exceção das duas últimas edições, são encontradas as mesmas características de composição: notas ou mensagens da redação e um artigo de cunho geral ou legislativo relativo à escola secundária; os artigos das áreas específicas; e para finalizar, o relatório ou noticiário da Cades, seção que eram descritas as atividades da Campanha e ocorria a divulgação de datas de eventos. Em algumas edições encontramos o Consultório da Cades, seção destinada às respostas das correspondências de professores que expressavam suas dúvidas sobre conteúdos específicos de suas disciplinas.

No Quadro 1, estão relacionados os artigos de ensino de Matemática, com seus respectivos autores. Sobre alguns destes últimos, foi possível apresentarmos informações sobre sua área de atuação profissional. 
Quadro 1- Artigos de Matemática publicados na revista Escola Secundária

\begin{tabular}{|c|c|c|c|}
\hline $\mathbf{N}^{\mathbf{o}}$ & Data & Título do Artigo & Autor(es) \\
\hline 01 & Jun/1957 & A Matemática na Escola Secundária & $\begin{array}{l}\text { Eleonora Lobo Ribeiro - bacharel em } \\
\text { Matemática pela FNFi, atuou no Ensino } \\
\text { Secundário em escolas municipais cario- } \\
\text { cas e no CAp da FNFi da antiga Universi- } \\
\text { dade do Brasil (RJ). }\end{array}$ \\
\hline 02 & Set/1957 & Voltemos ao mercador de vinho & $\begin{array}{l}\text { Malba Tahan - pseudônimo do professor } \\
\text { Júlio César de Mello e Souza (1895-1974) } \\
\text { do Colégio Pedro II. Catedrático da Fa- } \\
\text { culdade Nacional de Arquitetura da antiga } \\
\text { Universidade do Brasil (RJ), autor de } \\
\text { livros didáticos e paradidáticos de Mate- } \\
\text { mática. }\end{array}$ \\
\hline \multirow[t]{2}{*}{03} & \multirow[t]{2}{*}{ Dez/1957 } & Plano de Curso de Matemática & Eleonora Lobo Ribeiro \\
\hline & & $\begin{array}{l}\text { Ensinando Matemática e contando } \\
\text { história }\end{array}$ & $\begin{array}{l}\text { França Campos (Ismael França Campos) - } \\
\text { foi catedrático de Metodologia do Cálculo } \\
\text { no Instituto de Educação da antiga Uni- } \\
\text { versidade do Brasil (RJ). Lecionou Mate- } \\
\text { mática, Física, Ciências e Música no Co- } \\
\text { légio Metodista Bennett (RJ), entre } 1933 \text { e } \\
1962 \text {. }\end{array}$ \\
\hline \multirow[t]{2}{*}{04} & \multirow[t]{2}{*}{ Mar/1958 } & A definição da Matemática & Malba Tahan \\
\hline & & $\begin{array}{l}\text { Sobre o ensino da Geometria na Es- } \\
\text { cola Secundária }\end{array}$ & $\begin{array}{l}\text { Thales Mello Carvalho (1913-1961) - } \\
\text { professor catedrático da Faculdade Nacio- } \\
\text { nal de Ciências Econômicas da antiga } \\
\text { Universidade do Brasil (RJ). Foi diretor } \\
\text { do Departamento de Educação Primária } \\
\text { do MEC e autor de livros didáticos. }\end{array}$ \\
\hline \multirow[t]{2}{*}{05} & \multirow[t]{2}{*}{ Jun/1958 } & $\begin{array}{l}\text { A Aritmética e a Psicologia da } \\
\text { Aprendizagem }\end{array}$ & $\begin{array}{l}\text { João de Souza Ferraz (1903-1988) - psi- } \\
\text { cólogo e professor, escreveu livros na área } \\
\text { da psicologia. }\end{array}$ \\
\hline & & $\begin{array}{l}\text { A Demonstração Matemática na Edu- } \\
\text { cação do Adolescente }\end{array}$ & Eleonora Lobo Ribeiro \\
\hline
\end{tabular}




\begin{tabular}{|c|c|c|c|}
\hline \multirow[t]{2}{*}{06} & \multirow[t]{2}{*}{ Set/1958 } & O Período Primitivo da Matemática & Thales Mello Carvalho \\
\hline & & $\begin{array}{l}\text { O Material Didático no Ensino da } \\
\text { Matemática }\end{array}$ & $\begin{array}{l}\text { Manuel Jairo Bezerra - bacharel e licenci- } \\
\text { ado em Matemática pela FNFi, foi profes- } \\
\text { sor do Colégio Pedro II e autor de livros } \\
\text { didáticos de Matemática }\end{array}$ \\
\hline \multirow[t]{2}{*}{07} & \multirow[t]{2}{*}{ Dez/1958 } & $\begin{array}{l}\text { Sugestões Para o Ensino da Geome- } \\
\text { tria Dedutiva }\end{array}$ & $\begin{array}{l}\text { Antonio Rodrigues (1918-2003) - bacha- } \\
\text { rel e licenciado em Matemática pela } \\
\text { FFCL da USP; catedrático de Geometria } \\
\text { na Faculdade de Filosofia da URGS - } \\
\text { atualmente UFRGS. Autor de livro didáti- } \\
\text { co de Matemática de Ensino Superior. }\end{array}$ \\
\hline & & Provas Parciais de Matemática & $\begin{array}{l}\text { Diversos Autores - comissão de professo- } \\
\text { res da Comissão de Orientação do Ensino } \\
\text { de Matemática da ISES de Fortaleza (CE) }\end{array}$ \\
\hline 08 & Mar/1959 & $\begin{array}{l}\text { O Ensino da Geometria Dedutiva na } \\
\text { Escola Secundária }\end{array}$ & $\begin{array}{l}\text { Martha Blauth Menezes - professora do } \\
\text { CAp e de Didática Especial de Matemáti- } \\
\text { ca e Prática de Ensino da Matemática na } \\
\text { Faculdade de Filosofia da URGS, Porto } \\
\text { Alegre (RS). }\end{array}$ \\
\hline \multirow[t]{2}{*}{09} & \multirow[t]{2}{*}{ Jun/1959 } & A Suposta Aridez da Matemática & $\begin{array}{l}\text { Júlio César de Mello e Souza - idem Mal- } \\
\text { ba Tahan }\end{array}$ \\
\hline & & A Matemática e a História Natural & $\begin{array}{l}\text { Neusa Feital - colaboradora da Rádio } \\
\text { MEC }\end{array}$ \\
\hline \multirow[t]{2}{*}{10} & \multirow[t]{2}{*}{ Set/1959 } & $\begin{array}{l}\text { Programa de Matemática para as } \\
\text { Classes Experimentais do Colégio de } \\
\text { Aplicação da F.N.Fi. }\end{array}$ & Eleonora Lobo Ribeiro \\
\hline & & $\begin{array}{l}\text { O Material Didático no Ensino da } \\
\text { Geometria }\end{array}$ & $\begin{array}{l}\text { José Teixeira Baratojo - professor e autor } \\
\text { de livros didáticos de Matemática; bacha- } \\
\text { rel e licenciado em Matemática, atuou } \\
\text { com professor na Pontifícia Universidade } \\
\text { Católica do Rio Grande do Sul - PUC/RS. }\end{array}$ \\
\hline \multirow[t]{2}{*}{11} & \multirow[t]{2}{*}{ Dez/1959 } & Aprendei as Matemáticas & $\begin{array}{l}\text { Monsenhor Bruno de Colares (1895-1983) } \\
\text { - foi reitor do Instituto Católico de Tou- } \\
\text { louse, cidade da França. }\end{array}$ \\
\hline & & $\begin{array}{l}\text { Uma Experiência do Estudo Dirigido } \\
\text { em Matemática }\end{array}$ & $\begin{array}{l}\text { May Lacerda de Brito Monnerat - profes- } \\
\text { sora do CAp da FNFi da antiga Universi- } \\
\text { dade do Brasil (RJ). }\end{array}$ \\
\hline \multirow[t]{2}{*}{12} & \multirow[t]{2}{*}{ Mar/1960 } & Estudo Dirigido em Matemática & $\begin{array}{l}\text { Sylvia Barbosa - professora do CAp da } \\
\text { FNFi da antiga Universidade do Brasil } \\
\text { (RJ). }\end{array}$ \\
\hline & & Exemplos de Estudo Dirigido em & Anna Averbuch - professora do CAp da \\
\hline
\end{tabular}




\begin{tabular}{|c|c|c|c|}
\hline & & Matemática & $\begin{array}{l}\text { FNFi da antiga Universidade do Brasil } \\
\text { (RJ). }\end{array}$ \\
\hline & & Círculo e Circunferência & Pedro Pinto e Malba Tahan \\
\hline \multirow[t]{2}{*}{13} & \multirow[t]{2}{*}{ Jun/1960 } & $\begin{array}{l}\text { O Ensino de Estatística nas Escolas } \\
\text { Holandesas }\end{array}$ & Lucas N.H. Bunt \\
\hline & & $\begin{array}{l}\text { Ainda a Geometria Euclidiana Para } \\
\text { os Atuais Ginasianos? }\end{array}$ & $\begin{array}{l}\text { Osvaldo Sangiorgi - professor do ensino } \\
\text { secundário e da Universidade Mackenzi } \\
\text { (SP) e autor de livros didáticos }\end{array}$ \\
\hline \multirow[t]{2}{*}{14} & \multirow[t]{2}{*}{ Set/1960 } & O Medo da Matemática & Júlio César de Mello e Souza \\
\hline & & $\begin{array}{l}\text { Análise de Provas Parciais de Mate- } \\
\text { mática }\end{array}$ & $\begin{array}{l}\text { Comissão de Professores de Orientação do } \\
\text { Ensino de Matemática da ISES de Vitória } \\
\text { (ES) }\end{array}$ \\
\hline \multirow[t]{2}{*}{15} & \multirow[t]{2}{*}{ Dez/1960 } & Sistemas de Equações Lineares & $\begin{array}{l}\text { Leônidas Hegenberg - professor do Insti- } \\
\text { tuto Tecnológico de Aeronáutica. }\end{array}$ \\
\hline & & $\begin{array}{l}\text { Matemática para a } 3^{\mathrm{a}} \text { e } 4^{\mathrm{a}} \text { Séries Gi- } \\
\text { nasiais }\end{array}$ & $\begin{array}{l}\text { Luiz Alberto dos Santos Brasil - graduado } \\
\text { em Engenharia, foi professor de Matemá- } \\
\text { tica com contribuições publicadas sobre a } \\
\text { Didática da Matemática segundo o ponto } \\
\text { de vista piagetiano e responsável por cur- } \\
\text { sos da Cades, estado do Ceará. }\end{array}$ \\
\hline \multirow[t]{2}{*}{16} & \multirow[t]{2}{*}{ Mar/1961 } & $\begin{array}{l}\text { O Ensino das Médias Aritmética, } \\
\text { Geométrica e Harmônica }\end{array}$ & Sylvio de Souza Borges \\
\hline & & Estudo Dirigido na $1^{\text {a }}$ Série Ginasial & $\begin{array}{l}\text { Martinho da Conceição Agostinho - pro- } \\
\text { fessor do CAp da FNFi da antiga Univer- } \\
\text { sidade do Brasil (RJ). }\end{array}$ \\
\hline \multirow[t]{3}{*}{17} & \multirow[t]{3}{*}{ Jun/1961 } & $\begin{array}{l}\text { O Ensino da Matemática por Cami- } \\
\text { nhos Concretos }\end{array}$ & $\begin{array}{l}\text { Ladyr Anchieta da Silveira - foi professo- } \\
\text { ra de Matemática da Universidade Federal } \\
\text { de Santa Maria - UFSM, do Rio Grande } \\
\text { do Sul. }\end{array}$ \\
\hline & & $\begin{array}{l}\text { Exposição de Material Didático para } \\
\text { o Ensino da Matemática }\end{array}$ & Manuel Jairo Bezerra \\
\hline & & $\begin{array}{l}\text { Plano Experimental de Estudo Dirigi- } \\
\text { do }\end{array}$ & $\begin{array}{l}\text { Jair Leite Marins - professor do Ginásio } \\
\text { Estadual Prof. Clóvis Monteiro - RJ }\end{array}$ \\
\hline 18 & Sem data & $\begin{array}{l}\text { Problemas de Aprendizagem da Ma- } \\
\text { temática }\end{array}$ & João Baptista da Costa \\
\hline 19 & Sem data & $\begin{array}{l}\text { O Método do Laboratório em Mate- } \\
\text { mática }\end{array}$ & Malba Tahan \\
\hline
\end{tabular}

Fonte: Adaptado de Baraldi e Gaertner (2013, p. 79-80) 
Para o ensino da Matemática, constata-se que muitas das orientações dadas em vários artigos são encontradas em documentos e propostas educativas para os dias de hoje. A utilização de recursos didáticos é ainda adotada nas escolas de educação básica atualmente, como uma imprescindível ferramenta para a compreensão dos conceitos matemáticos. Em algumas instituições escolares de ensino básico e superior há laboratórios de matemática onde são desenvolvidas atividades práticas. A confecção e a adoção de materiais manipuláveis, como proposto por Manoel Jairo Bezerra em seus textos, ainda é bastante salientada nos encaminhamentos metodológicos descritos atualmente.

A relação da Matemática com outras áreas de conhecimento, para que seu ensino e sua aprendizagem fossem mais significativos, já era uma necessidade alertada pelos professores à época na revista. Todavia, uma das orientações dadas em vários artigos, a da utilização do método do estudo dirigido como técnica de ensino, desapareceu das instituições escolares nas décadas seguintes. Em diversos números da Revista, é insistente o chamado ao professor para adotar tal método, como também sempre é enfatizado que se faz necessária uma revisão de sua metodologia e que o ensino secundário deve ser renovado.

Na obra de Baraldi e Gaertner (2013) há uma síntese de cada um dos artigos citados no quadro.

\section{CONSIDERAÇÕES FINAIS}

O desenvolvimento da Campanha de Aperfeiçoamento e Difusão do Ensino Secundário no período de 1953 a 1971 permitiu que centenas de professores tivessem acesso à formação profissional para atuarem no ensino secundário. Numa época em que ocorreu um aumento significativo de estudantes no nível secundário, principalmente nas cidades do interior do Brasil, e a falta de professores formados em cursos superiores de graduação para atender a essa demanda, a formação oferecida pelos cursos da Cades atendeu às necessidades das escolas secundárias espalhadas pelo país, ou seja, a qualificação dos seus professores.

Quanto ao número expressivo de livros publicados durante a existência da Campanha, muitos deles manuais de "como ensinar", podemos afirmar que a preocupação era, sobretudo, com "as didáticas", ou seja, com as orientações pedagógicas das disciplinas escolares, o que de certo modo, servia como forma de regulação do que deveria ser o ensino secundário e o professor que nele atuaria. Estas obras trazem as orientações pedagógicas e metodológicas que, acreditava-se à época, serem as adequadas para o ensino secundário. Especificamente, na área da Matemática, duas importantes orientações didáticas foram difundidas aos professores: a adoção da técnica do estudo dirigido e a utilização de recursos didáticos diferenciados para promover a aprendizagem matemática.

Entendemos que o que apresentamos nesse artigo é uma das facetas da Cades ou, porque não dizer, uma das Cades dentre as muitas que existiram no país. Ao considerarmos a imensidão e a diversidade do Brasil, podemos pensar que em cada localidade onde a divulgação da Campanha se deu, seus objetivos foram incorporados e adaptados a aquela realidade. Isso pode ser percebido nas inúmeras narrativas de professores que os diferentes trabalhos do Grupo de Pesquisa História Oral e Educação Matemática - Ghoem - mobilizam. A tese de Oliveira (2013) corrobora essa afirmação ao constituir um texto sobre a Cades usando diversas narrativas, mostrando assim as diferentes atuações dos professores durante a Campanha, 
bem como o acesso ou não às suas obras. Em trabalho anterior, Finato, Baraldi e Morais (2012) também já apontavam para essa possibilidade. Assim, percebemos que de total desconhecida e negligenciada, essa maneira emergencial e remedial de formar professores e difundir os ideais educacionais da segunda metade do século XX, está sendo contemplada na história da educação matemática brasileira.

\section{REFERÊNCIAS}

BARALDI, I.M. Retraços da Educação Matemática na Região de Bauru: uma história em construção. 2003. Tese (Doutorado em Educação Matemática) - Instituto de Geociências e Ciências Exatas, UNESP, Rio Claro, 2003.

BARALDI, I.M.; GAERTNER, R. Textos e Contextos: um esboço da Cades na História da Educação (Matemática). Blumenau: Edifurb, 2013.

GAERTNER, R. A matemática escolar em Blumenau (SC) no período de 1889 a 1968: da Neue Deutsche Schule à Fundação Universidade Regional de Blumenau. 2004. 227 f. Tese (Doutorado em Educação Matemática) - Instituto de Geociências e Ciências Exatas, UNESP, Rio Claro, 2004.

FINATO, J. A. R.; BARALDI, I. M.; MORAIS, M. B. de. CADES: um ensaio sobre uma formação de professores de Matemática. Perspectivas da Educação Matemática, v. 5, p. 88$100,2012$.

MATTOS, L.A. A nossa revista. Escola Secundária, Rio de Janeiro, ano I, n. 1, p. 5-9, 1957.

OLIVEIRA, F. D. de. Hemera: sistematizar textualizações, possibilitar narrativas. 2013. Tese (Doutorado em Educação para Ciências). Unesp, Faculdade de Ciências, Bauru, 2013. 176 p.

PINTO, D. C. Campanha de Aperfeiçoamento e Difusão do Ensino Secundário: uma trajetória bem-sucedida?. In: MENDONÇA, A. W.; XAVIER, L. N. (Orgs.). Por uma política de formação do magistério nacional: o Inep/MEC dos anos 1950/1960. Brasília: Instituto Nacional de Estudos e Pesquisas Educacionais Anísio Teixeira, 2008. 260 p. (Coleção Inep 70 anos, v. 1) 